Available online at GSC Online Press Directory

GSC Biological and Pharmaceutical Sciences

e-ISSN: 2581-3250, CODEN (USA): GBPSC2

Journal homepage: https://www.gsconlinepress.com/journals/gscbps

(RESEARCH ARTICLE)

\title{
Knowledge, attitude and practice of health care workers on antibiotic resistance and usage in the Gambia
}

Bakary Sanneh 1,\#, , , Haruna S. Jallow 1,\# ,Yankuba Singhateh 2, Babanding Sabally ${ }^{3}$, Alhagie Papa Sey 1 , Amadou Woury Jallow ${ }^{2}$, Tijan Jallow ${ }^{3}$, Ignatius Baldeh ${ }^{1}$, Sana M. Sambou ${ }^{2}$ and Sharmila Lareef Jah ${ }^{4}$, \#

\author{
${ }^{1}$ National Public Health Laboratories, Ministry of Health, The Gambia. \\ ${ }^{2}$ Epidemiology and Disease Control Unit, Ministry of Health, The Gambia. \\ ${ }^{3}$ National Pharmaceutical Services, Ministry of Health, The Gambia. \\ ${ }^{4}$ World Health Organization, Country Office, The Gambia. \\ \#Authors contributed equally for the production of this research work.
}

Publication history: Received on 31 September 2020; revised on 16 October 2020; accepted on 21 October 2020

Article DOI: https://doi.org/10.30574/gscbps.2020.13.2.0177

\begin{abstract}
Introduction: Irrational prescription and use of antibiotics are found to be risk factors to the spread of antibiotic resistance. Studies have shown that more than half of the admitted patients at the Paediatric Department of the Edward Francis Small Teaching Hospital (EFSTH) in The Gambia have been treated with antibiotics in the year 2015 alone. It was also evident that $74.5 \%$ of clinical isolates were resistant to ampicillin which was the most prescribed antibiotic among these patients. Therefore, the need to assess health care workers' knowledge, attitude and practices on the phenomenon of anti-microbial resistance (AMR) and antibiotic usage in the Gambia.

Materials and Methods: This cross-sectional study was conducted using self-administered questionnaires which were adopted from related studies. The questionnaires were administered at 60 randomly selected health facilities (both public and private) from around the country with a sample size of 225 respondents in 2016 . Descriptive analyses were performed for each study variable and rates were reported as percentages. The results are presented in the form of contingency tables with their respective related Chi-squared $(\chi 2)$ statistics values. The interpretations of the P-values are based on the less than or equal to 0.05 (5\%) significance level.

Result: The study revealed that $63.27 \%$ of the respondents were nurses, $41.7 \%$ of them had a work experience between 0-4 years of service and most of the respondents work in the urban areas. Most of health care workers have knowledge on the right usage of antibiotics and understood that frequent usage of antibiotic could compromise the effectiveness of antibiotics. The study found $94.14 \%$ of the health care workers agreed there exists antibiotic abuse in both hospital and community settings. However, $23.08 \%$ of the respondents are not aware those antibiotics are not effective against viral infections such as common cold.

Conclusion: Therefore, majority of the health care workers had knowledge about antibiotic resistance and are aware of the frequent and abuse of antibiotic use could contribute to the development of antibiotic resistance in the country. However, they were less informed of the cost involved in the treatment and management of multidrug resistance patients using fewer and expensive antibiotics. Moreover, some of the health care workers had misconception on the treatment of viral infections with antibiotics (such as antibacterial) and there also exists disproportionate distribution of trained health workers in the country. Therefore, refresher training on prudent usage of antibiotics for health care workers especially doctors and nurses must be strengthened.
\end{abstract}

\footnotetext{
* Corresponding author: Bakary Sanneh

National Public Health Laboratories, Ministry of Health, The Gambia. 
Keywords: Knowledge Attitude Practice; Antibiotic Resistance; Antibiotic Usage; Health Care Workers; The Gambia.

\section{Background}

Antibiotics have played a great impact in the field of medical science and healthcare practice, particularly in the treatment of infectious diseases. The treatment of infectious pathogen with antibiotic has been followed with evolution of antimicrobial resistance [1]. Thus, limiting the choice of antibiotics and increased the cost of treatment and care of patients infected with such antibiotic resistance pathogens in the globe. A study conducted in the hospital emergency department in Germany found 36.5\%(137/469) of the urine culture isolates were of multidrug resistance pathogens and the associated risk factors to these antibiotic resistance were treated with antibiotic in last 30 days, hospitalization in within 30 days, exposure to hospital instrumentation such as catheterization[2]. These same researchers have shown evidence that prevalence of resistance of pathogen to antimicrobials was proportionate to the number of risk factors posed upon the human host [2]. Furthermore, a systematic review of risk factors for acquiring multidrug resistance organisms in urinary tract infections found that factors such as previous antibiotic usage, urinary catherization, and previous hospitalization and nursing home residence were among the most significantly associated risk factor [3].These researchers have established that most common risk factor which were identified in from 16/20 studies was the previous use of antibiotics [3].A study in Ethiopia also found that factors such as self-antibiotic prescription, poor patients' adherence to prescribed antimicrobials and prescribers' low awareness about AMR, antibiotics over use, lack of prescribers access to local antibiotic data, contribute to the development of AMR in the country[4]. It was also discovered that the motives for excessive prescription of antibiotics were associated with patient drive, treatment failures, unknown febrile illnesses and upper respiratory tract infections [4]. Majority of the participants (doctors, nurses, medical students, etc.) in studies conducted in Ethiopia and Peru, had good knowledge and awareness about antibiotic resistance as a global problem, yet they were lowly informed of trends of antibiotic resistance in hospitals and their countries[4,5]. This finding is similar to a systematic review wherein $80.9 \%$ of health care practioners from 15 studies were found knowledgeable of issues related to antibiotic use although only $39.6 \%$ knew the local resistance patterns in their health facilities [6].

Studies in The Gambia have revealed that antibiotic resistant pattern for ESBL producing enterobacteriae among food handler [7], antibiotic susceptibility of Streptococcus pneumoniae and Staphylococcus aureus among infants[8];multidrug resistance tuberculosis resistance[9]; antibiotis susceptibility pattern of Helicobacter pylori [10]; Salmonella spp resistance gene and susceptibility in human and animal[11,12]; Burkholderia cepacia and Klebsiella spp resistance in clinical settings[13,14]. It was reported that over more than half of the patients admitted at department of paediatrics of the Edward Francis Small Teaching Hospital were treated with at least one antibiotic and most of their prescriptions were empirically based [14]. This study also provided evidence that the most prescribed and used antibiotic (ampicillin) was proportionately having the highest resistance to isolated pathogens [14]. Similarly, another study has found high proportion of empirical patient treatment with antibiotic at outpatient for children and neonates in The Gambia [15]. Some of the risk factors for the prevalence of the antibiotic resistance in country have been associated with usage in the last 3 months and the frequency of antibiotic prescriptions, vertical transmission, nosocomical and zoonotic[7,12,13].The World Health Organization's Joint External Evaluation report 2017 found limited antibiotic stewardship programs [16]. Hence, there exists limited information about the knowledge, practice and aware of the health workers notably doctors and nurses who do consultations and prescription of antibiotics for patients in the country and which could be used to inform the development of AMR stewardship programme.

\section{Methods}

\subsection{Study Population, Sample Selection, Sample Size}

The study was a cross-sectional survey of health care workers in the system involving public hospitals, major and minor health centers, community clinics, service (security) and private clinics. Self-administered questionnaire was administered at each participating health facilities. Questionnaires were distributed during working hours and were answered on the spot and there was no allowance for taking part in the survey. The following formula was used to obtain a representative sample size estimate for the proposed study:

$\mathrm{N}=\mathrm{z} 2 \mathrm{P}(1-\mathrm{P}) / \mathrm{e} 2$

Where $\mathrm{n}=$ number to sample

$\mathrm{Z} 2=(1.96) 2$ for $95 \%$ Confidence (i.e. $\alpha=0.05), P=$ "best guess" for prevalence (i.e. $15 \%$ ) 
$\mathrm{e}=$ maximum tolerable error for the prevalence estimate is $5 \%$ and at type 1 error of $5 \%$

[In order to obtain a narrower interval, a maximum tolerable error of 0.05 will be used. The $15 \%$ prevalence (best guess) is the estimated average health worker awareness about antibiotic resistance]

$\mathrm{n}=1.962 * 0.15 *(1-0.15) / 0.05 * 0.05=196 \approx 200$

The current list of functional health facilities and hospitals in the country was used in the sampling frame; a stratified random sample of 200 health care workers was recruited from health facilities. The health facilities were categorised into public health centres (61 or 44\%), hospitals (10 or 8\%), and community/private \& NGO facilities (54 or 39\%), and service clinics (14 or 10\%) and were proportionally and randomly selected. Each category was allocated its commensurate number of potential participants. Public health centres constituted 44\% participants, and 10\% were from the service clinics respectively. In each stratum, a simple random sample was drawn using random numbers from excel. Health workers working within the hospital or health facility during working hours and consented were included as participants.

\subsection{Ethical consideration}

Clearance for the study was sought from the The Gambia Government joint Medical Research Council Ethics Committee and from the Ministry of Health. All the respondents were consented before participation in the study. The data collected was anonymized before analysis.

\subsection{Data analysis}

Data was entered and analyzed using Stata, version 12. Descriptive analyses were performed for each and every study variable and rates are reported as percentages. They were presented in the form of contingency tables with associated chi-squared $(\chi 2)$ statistics. The interpretations of the p-values are based on the $0.05(5 \%)$ significance level. The overall prevalence of the observed variables of interest was reported with $95 \%$ confidence intervals

\section{Result}

Table 1 Demographic information of Health Care Workers

\begin{tabular}{|l|l|l|}
\hline & & $\mathbf{N}(\mathbf{\%})$ \\
\hline Gender & Male & $136(60.18)$ \\
\hline & Female & $88(38.94)$ \\
\hline & Nurse & $143(63.27)$ \\
\hline & Auxilary Nurse & $37(16.37)$ \\
\hline & Doctor & $13(5.75)$ \\
\hline & Laboratory Personnel & $13(5.75)$ \\
\hline & Public Health Officer & $3(1.33)$ \\
\hline & Pharmacy Personnel & $14(6.19)$ \\
\hline & $1-4 y e a r s$ & $93(41.70)$ \\
\hline & $5-9 y e a r s$ & $54(24.22)$ \\
\hline & $10-14 y e a r s$ & $26(11.66)$ \\
\hline & $15-19 y e a r s$ & $21(9.42)$ \\
\hline & $20-24 y e a r s$ & $11(4.93)$ \\
\hline Health Region & Above24years & $18(8.07)$ \\
\hline & Western One (1) & $72(31.86)$ \\
\hline & Western Two (2) & $42(18.58)$ \\
\hline & Lower River & $19(8.41)$ \\
\hline & North Bank & $33(14.60)$ \\
\hline & Central River & $31(13.72)$ \\
\hline & & \\
\hline & &
\end{tabular}


Majority of the respondents were male workers 136 (60.18). 93 (41.70\%) of the studied participants have a working experience of between 0-4 years. Most of the nurses, 143 (63.27\%) followed by Pharmacy personnel 14(6.19\%), doctors 13 (5.75), Laboratory personnel 13 (5.75), Public health officers 3 (1.33), and 37(16.37\%) of auxiliary nurses were also involved in this studied. Most of the respondents were residing in Western Coast Health Region One 72 (31.86\%) of the country followed by Western Coast Health Region Two 42 (18.58\%), North Bank Region 33 (14.60\%), Central River Region 31 (13.72\%), Upper River Region 28 (12.39\%) and Lower River Region 19 (8.41\%). Only 12.9\% (29/225) of the health workers were found to be in the medical practice for more than 20 years of services.

Overall, $75.91 \%$ of the respondents gave the correct response when asked about whether antibiotic use speeds up recovery from colds and cough. However, compared to other cadres, auxiliary nurses, only $50 \%$ of whom got the right answer, had performed poorer than the other cadres $(\chi 2=18.1, p=0.003)$. On the question of whether frequent antibiotic use decreases efficacy of treatment when using the antibiotic again, only $66.97 \%$ of respondents answered "yes". Auxiliary nurses performed significantly poorer (45.95\%) followed by Pharmacy staffs at $61.54 \%(\chi 2=14.8$, $\mathrm{p}=0.011$ ).Overall $96.85 \%$ of respondents gave the correct answer when asked whether antibiotics cure bacterial infections and there was no significant difference in the performance of the different cadres $(\chi 2=6.52, \mathrm{p}=0.259)$. On the question of whether antibiotics cure viral infections, $76.92 \%$ of respondents answered "no" with auxiliary nurses performing poorer (57.14\%) than the other cadres, followed by laboratory personnel and Pharmacy staffs at $61.54 \%$ and $64.29 \%$ respectively $(\chi 2=15.9, \mathrm{p}=0.007$.

Table 2 Health workers' knowledge on antibiotic usage.

\begin{tabular}{|c|c|c|c|c|}
\hline \multirow{2}{*}{ Question (Right Answer) } & \multirow{2}{*}{$\begin{array}{l}\text { Total\% } \\
(n / N)\end{array}$} & \multicolumn{3}{|l|}{$\%(n / N)$} \\
\hline & & Nurse & Auxilary Nurse & Doctor \\
\hline $\begin{array}{l}\text { Do you think the use of antibiotics will speed up } \\
\text { the recovery of cold, cough? (no) }\end{array}$ & $75.91(167 / 220)$ & $80.99(115 / 142)$ & $50(18 / 36)$ & $84.62(11 / 13)$ \\
\hline $\begin{array}{l}\text { Do you think frequent use of antibiotics will } \\
\text { decrease efficacy of treatment when using the } \\
\text { antibiotic again? (yes) }\end{array}$ & $66.97(148 / 221)$ & $68.31(97 / 142)$ & $45.95(17 / 37)$ & $92.31(12 / 13)$ \\
\hline Can antibiotics cure bacterial infections? (yes) & $96.85(215 / 222)$ & $98.59(140 / 142)$ & $91.89(34 / 37)$ & $100(13 / 13)$ \\
\hline Can antibiotics cure viral infections? (no) & $76.92(170 / 221)$ & $82.52(118 / 143)$ & $57.14(20 / 35)$ & $92.31(12 / 13)$ \\
\hline $\begin{array}{l}\text { Is the efficacy better if the antibiotics are newer } \\
\text { and more costly? (no) }\end{array}$ & $53.3(113 / 212)$ & $48.55(67 / 138)$ & $54.55(18 / 33)$ & $83.33(10 / 12)$ \\
\hline
\end{tabular}

Table 3 Health workers' attitude and public education on usage of antibiotics

\begin{tabular}{|c|c|c|c|c|c|}
\hline \multirow[b]{2}{*}{ Question (Right Answer) } & \multicolumn{3}{|l|}{$\%(n / N)$} & \multirow[b]{2}{*}{$\chi^{2}$} & \multirow[b]{2}{*}{$\mathbf{P}$} \\
\hline & $\begin{array}{l}\text { Laboratory } \\
\text { Personnel }\end{array}$ & $\begin{array}{l}\text { Public Health } \\
\text { Officer }\end{array}$ & $\begin{array}{l}\text { Pharmacy } \\
\text { staff }\end{array}$ & & \\
\hline $\begin{array}{l}\text { Do you think the use of antibiotics will } \\
\text { speed up the recovery of cold, cough? (no) }\end{array}$ & $69.23(9 / 13)$ & $66.67(2 / 3)$ & $92.31(12 / 13)$ & 18.1 & 0.003 \\
\hline $\begin{array}{l}\text { Do you think frequent use of antibiotics will } \\
\text { decrease efficacy of treatment when using } \\
\text { the antibiotics again? (yes) }\end{array}$ & $84.62(11 / 13)$ & $100(3 / 3)$ & $61.54(8 / 13)$ & 14.8 & 0.011 \\
\hline $\begin{array}{l}\text { Can antibiotics cure bacterial infections? } \\
\text { (yes) }\end{array}$ & $92.31(12 / 13)$ & $100(3 / 3)$ & $92.86(13 / 14)$ & 6.52 & 0.259 \\
\hline Can antibiotics cure viral infections? (no) & $61.54(8 / 13)$ & $100(3 / 3)$ & $64.29(9 / 14)$ & 15.9 & 0.007 \\
\hline $\begin{array}{l}\text { Is the efficacy better if the antibiotics are } \\
\text { newer and more costly? (no) }\end{array}$ & $53.85(7 / 13)$ & $50(1 / 2)$ & $71.43(10 / 14)$ & 7.48 & 0.187 \\
\hline
\end{tabular}

$94.14 \%$ of the respondents provided the correct answers to the questions on whether there exists antibiotics abuse, but there was no statistically significant difference in the performance of the different cadres $(\chi 2=3.61, p=0.607)$. 88.24\% 
of the respondents provided the correct answers to the questions on whether antibiotic resistance has become a problem in The Gambia, but there was no statistically significant difference in the performance of the different cadres $(\chi 2=5.79, \mathrm{p}=0.328)$. On whether abuse of antibiotics has become the main leading cause to bacterial resistance, $90.37 \%$ of respondents answered "agree" but there was no statistically significant difference in the performance of the different cadres $(\chi 2=6.28, \mathrm{p}=0.28) .86 .82 \%$ of the respondents provided the correct answers to the questions on whether antibiotic resistance affects their family's health, but there was no statistically significant difference in the performance of the different cadres $(\chi 2=9.78, \mathrm{p}=0.082)$. On whether it is necessary to carry out large-scale 'antibiotics campaign' promotion, $92.66 \%$ of respondents in favored of launching more antibiotic awareness campaign, with public health officers performing much poorer than the other cadres $(\chi 2=18.7, p=0.002$.

Table 3 Health workers' attitude and public education on usage of antibiotics.

\begin{tabular}{|c|c|c|c|c|}
\hline \multirow{2}{*}{ Question (Right Answer) } & \multirow{2}{*}{ Total\%(n/N) } & \multicolumn{3}{|l|}{$\%(n / N)$} \\
\hline & & Nurse & Auxilary Nurse & Doctor \\
\hline There is abuse on antibiotics at present. (agree) & $94.14(209 / 222)$ & $94.37(134 / 142)$ & $89.19(33 / 37)$ & $100(13 / 13)$ \\
\hline $\begin{array}{l}\text { Antibiotic resistance has become a problem in The } \\
\text { Gambia. (agree) }\end{array}$ & $88.24(195 / 221)$ & $87.32(124 / 142)$ & $83.78(31 / 37)$ & $100(13 / 13)$ \\
\hline $\begin{array}{l}\text { Abuse of antibiotics has become the main leading } \\
\text { cause to bacterial resistance. (agree) }\end{array}$ & $90.37(197 / 218)$ & $91.49(129 / 141)$ & $80(28 / 35)$ & $100(13 / 13)$ \\
\hline $\begin{array}{l}\text { Antibiotic resistance affects you and your family's } \\
\text { health. (agree) }\end{array}$ & $86.82(191 / 220)$ & $87.32(124 / 142)$ & $75(27 / 36)$ & $100(13 / 13)$ \\
\hline $\begin{array}{l}\text { Necessary to carry out large-scale 'antibiotics } \\
\text { campaign' promotion. (agree) }\end{array}$ & $92.66(202 / 218)$ & $92.81(129 / 139)$ & $97.22(35 / 36)$ & $100(13 / 13)$ \\
\hline There is abuse on antibiotics at present. (agree) & 92.31(12/13) & $100(3 / 3)$ & $100(14 / 14)$ & 3.61 \\
\hline $\begin{array}{l}\text { Antibiotic resistance has become a problem in The } \\
\text { Gambia. (agree) }\end{array}$ & $100(12 / 12)$ & $66.67(2 / 3)$ & $92.86(13 / 14)$ & 5.79 \\
\hline $\begin{array}{l}\text { Abuse of antibiotics has become the main cause } \\
\text { leading to bacterial resistance. (agree) }\end{array}$ & $92.31(12 / 13)$ & $100(2 / 2)$ & $92.86(13 / 14)$ & 6.28 \\
\hline $\begin{array}{l}\text { Antibiotic resistance affects you and your family's } \\
\text { health. (agree) }\end{array}$ & $100(13 / 13)$ & $66.67(2 / 3)$ & $92.31(12 / 13)$ & 9.78 \\
\hline $\begin{array}{l}\text { Necessary to carry out large-scale 'antibiotics } \\
\text { campaign' promotion. (agree) }\end{array}$ & $92.31(12 / 13)$ & $33.33(1 / 3)$ & $85.71(12 / 14)$ & 18.7 \\
\hline
\end{tabular}

On whether antibiotics could be used when having common cold, only $26.01 \%$ of respondents gave the right answers, with auxiliary nurses performing better than the other cadres at $54.05 \%(\chi 2=23.6, p=<0.0001) .91 .82 \%$ of the respondents provided the correct answers to the questions on whether antibiotics could be used when having acute bronchitis, with doctors and public health officers performing significantly lower at $61.54 \%$ and $66.67 \%$ respectively $(\chi 2=22.5, \mathrm{p}=<0.0001) .83 .11 \%$ of the respondents provided the correct answers to the questions on whether antibiotics could be used when coughing up yellow/green sputum, but there was no statistically significant difference in the performance of the different cadres $(\chi 2=2.92, p=0.712) .87 \%$ of respondents provided the correct answer to the question on whether antibiotics could be used to treat sore throat, but there was no statistically significant difference in the performance of the different cadres $(\chi 2=9.79, \mathrm{p}=0.081) .73 .09 \%$ of respondents provided the correct answer to the questions on whether antibiotics could be used to treat cough with fever, but there was no statistically significant difference in the performance of the different cadres $(\chi 2=5.62, p=0.345)$. On whether antibiotics could be used when having a congested nose with headache, only $30.88 \%$ of respondents gave the right answer, with public health officers performing significantly better than the other cadres at $66.67 \%(\chi 2=17.4, p=0.004) .58 .53 \%$ of the respondents provided the correct answer to the question on whether antibiotics could be used when having acute bronchitis, with laboratory personnel and auxiliary nurses performing significantly better at $83.33 \%$ and $80 \%$ respectively ( $\chi 2=13.8, p=0.017)$. $76.82 \%$ of respondents provided the correct answer to the question on whether antibiotics could be used to treat cough lasting 2 weeks or more, but there was no statistically significant difference in the performance of the different cadres $(\chi 2=9.97, \mathrm{p}=0.076)$. 
Table 4 Health workers' practices for using antibiotic

\begin{tabular}{|c|c|c|c|c|}
\hline \multirow{2}{*}{ Question (Right Answer) } & \multirow{2}{*}{ Total\%(n/N) } & \multicolumn{3}{|l|}{$\%(n / N)$} \\
\hline & & Nurse & Auxilary Nurse & Doctor \\
\hline $\begin{array}{l}\text { Use antibiotics when having common cold } \\
\text { (always, often) }\end{array}$ & $26.01(58 / 223)$ & $18.18(26 / 143)$ & $54.05(20 / 37)$ & $23.08(3 / 13)$ \\
\hline Acute bronchitis(always, often) & $91.82(202 / 220)$ & $95.07(135 / 142)$ & $91.43(32 / 35)$ & $61.54(8 / 13)$ \\
\hline $\begin{array}{l}\text { Coughing up yellow/green sputum(always, } \\
\text { often) }\end{array}$ & $83.11(182 / 219)$ & $82.01(114 / 139)$ & $81.08(30 / 37)$ & $92.31(10 / 13)$ \\
\hline Sore throat(always, often) & $87(194 / 223)$ & $82.52(118 / 143)$ & $97.30(36 / 37)$ & $100(13 / 13)$ \\
\hline Cough with fever (always, often) & $73.09(163 / 223)$ & $72.03(103 / 143)$ & $67.57(25 / 37)$ & $100(13 / 13)$ \\
\hline Congested nose with headache (always, often) & $30.88(67 / 217)$ & $23.24(33 / 142)$ & $57.58(19 / 33)$ & $30.77(4 / 13)$ \\
\hline Coughing up white sputum (always, often) & $58.53(127 / 217)$ & $50.35(71 / 141)$ & $80(28 / 35)$ & $61.54(8 / 13)$ \\
\hline Cough lasting 2 weeks or more (always, often) & $76.82(169 / 220)$ & $70.42(100 / 142)$ & $86.11(31 / 36)$ & $92.31(12 / 13)$ \\
\hline
\end{tabular}

Table 4 health workers' practices for using antibiotic

\begin{tabular}{|l|l|l|l|l|l|}
\hline \multirow{2}{*}{ Question(Right Answer) } & \multicolumn{2}{l|}{$\%(\mathbf{l}$ (N) } & \multirow{2}{*}{$\chi^{2}$} & P \\
\cline { 2 - 5 } & Laboratory Personnel & Public Health Officer & Pharmacy staff & \\
\hline $\begin{array}{l}\text { Use antibiotics when having } \\
\text { common cold (always, often) }\end{array}$ & $46.15(6 / 13)$ & $33.33(1 / 3)$ & $14.29(2 / 14)$ & 23.6 & $<0.0001$ \\
\hline Acute bronchitis(always, often) & $84.62(11 / 13)$ & $66.67(2 / 3)$ & $100(14 / 14)$ & 22.5 & $<0.0001$ \\
\hline $\begin{array}{l}\text { Coughing up yellow/green } \\
\text { sputum(always, often) }\end{array}$ & $76.92(10 / 13)$ & $100(3 / 3)$ & $92.86(13 / 14)$ & 2.92 & 0.712 \\
\hline Sore throat(always, often) & $92.31(12 / 13)$ & $66.67(2 / 3)$ & $92.86(13 / 14)$ & 9.79 & 0.081 \\
\hline Cough with fever (always, often) & $76.92(10 / 13)$ & $66.67(2 / 3)$ & $71.43(10 / 14)$ & 5.62 & 0.345 \\
\hline $\begin{array}{l}\text { Congested nose with headache } \\
\text { (always, often) }\end{array}$ & $41.67(5 / 12)$ & $66.67(2 / 3)$ & $28.57(4 / 14)$ & 17.4 & 0.004 \\
\hline $\begin{array}{l}\text { Coughing up white sputum (always, } \\
\text { often) }\end{array}$ & $83.33(10 / 12)$ & $66.67(2 / 3)$ & $61.54(8 / 13)$ & 13.8 & 0.017 \\
\hline $\begin{array}{l}\text { Cough lasting 2 weeks or more } \\
\text { (always, often) }\end{array}$ & $83.33(10 / 12)$ & $100(3 / 3)$ & $92.86(13 / 14)$ & 9.97 & 0.076 \\
\hline
\end{tabular}

\section{Discussion}

\subsection{Demographic information of health care workers}

Two hundred and twenty-five (225) health care providers were enrolled in this study from six (6) regions of the country involving 60 health facilities in The Gambia. Majority of the participants were male which depicted the gender in balance of health care workers in the country. The larger number of the health workforce were found to be nurses; $180 / 225$ $(80 \%)$ of whom $37(16.37 \%)$ were auxiliary nurses. These show that there exist very poor doctors to the population ratio in rural country settings. Moreover, the rest of other cadres of health care providers, public health officers, pharmacy personnel and laboratory personnel 30/225 (13.02\%) were very few. Therefore, the study revealed that majority of the health care providers are nurses and the available few doctors are mainly concentrated in the urban 
centers. It was also established that most of health providers are in their early years of health care services and with very a few veteran workers.

\subsection{Health workers' knowledge on antibiotic usage}

The study revealed relevant information about knowledge, attitude and practices of health care workers on antibiotics usage and resistance as shown in (Table 3). Their knowledge on antibiotic resistance, inappropriate use and consequences are high as found in similar studies in India and Saudi Arabia [17, 18]. The study found that 75.91\% $(167 / 220)$ of the health care workers agreed that antibiotic use does not speed up recovery from colds and cough. However, compared to other cadres, auxiliary nurses (18/36) 50\% of whom got the right answer, had performed poorer than the other cadres with a significant value of $(\chi 2=18.1, p=0.003) .66 .97 \%$ of respondents who answered "yes" on whether frequent antibiotic use decreases efficacy of treatment when using the antibiotics again. Furthermore, auxiliary nurses performed significantly poorer (45.95\%) followed by Pharmacy staffs at $61.54 \%(\chi 2=14.8, p=0.011)$. It was also found that $(96.85 \%)$ of the respondents knew that antibiotics usage effectively cures bacterial infections. Therefore, it was manifested that no significant difference $(\chi 2=6.52, p=0.259)$ in the overall respondents of whether antibiotics cure bacterial infections in all health care cadres. Besides, majority $76.92 \%(170 / 221)$ were also found to be knowledgeable on the fact that antibiotic are not an effective treatment for viral diseases. Nevertheless, misunderstanding about the general role of antibiotics, that is the indication and effectiveness is clearly manifested as $23 \%$ of the respondents got it wrong that antibiotics are effective against viruses (Table 2). A similar study shows health care workers had misconceptions and a knowledge gap about the effectiveness of antibiotics against viruses [19]. However, auxiliary nurses performed poorer (57.14\%) than the other cadres, followed by laboratory personnel and Pharmacy staffs at $61.54 \%$ and $64.29 \%$ respectively $(\chi 2=15.9, \mathrm{p}=0.007) .53 .3 \%$ of our respondents were not aware that the efficacy of the treatment of AMR victims is better with newer antibiotics as in (Table 1). However, a study shows that health care workers are not aware of the expensiveness of the management of AMR victims. Our study found that, most of the doctors and trained nurses who are the main prescribers in the country have knowledge on the right usage of antibiotics and they understood that frequent usage of antibiotics can compromise the efficacy of the antibiotics and there is urgent need for training of health care workers.

\subsection{Health workers' attitude and public education on usage of antibiotics}

The study revealed that $94.14 \%$ of the health care workers agreed to the existence of antibiotics abuse, and there was no statistically significant difference in the performance of the different cadres $(\chi 2=3.61, p=0.607)$. Our finding is similar to a study done in Saudi Arabia where most of the respondents perceived AMR as a big problem in their routine work [17]. Moreover, $88.24 \%$ of the respondents had acknowledged that antibiotic resistance has become a problem in the country and there was no statistically significant difference in the performance of the different cadres $(\chi 2=5.79$, $\mathrm{p}=0.328$ ). This was also comparable with the study done in Peru were most of the respondents recognized AMR as a worldwide problem[5] The study results also found that $90.37 \%$ of the health care workers had agreed that abuse of antibiotics could be the main cause leading to bacterial resistance in the country and there was no significant difference in performance of the different cadres $(\chi 2=6.28, p=0.28)$. The study has shown that $86.82 \%$ of the respondents did agree that antibiotic resistance might affect their family's health. The over-use and or abuse of antibiotics were perceived both in hospital and community settings [5].Majority (92.66\%) of respondents gave the right answers to carry out large-scale 'antibiotics campaign' promotion. As also recommended in the Peruvian paper, that more antibiotic prescribing educational programs and local antibiotic guidelines should be available[5] Therefore, this study found that majority of the health care workers are aware that the attitude of antibiotic abuse could lead antibiotic resistance and are experiencing the antibiotic phenomena in the country. Besides, it was found in another study that, AMR development could be due to patients' poor adherence to prescribers' recommendation thus overuse of antibiotics [4]. They were also found to be aware that their families are at risk to antibiotic resistant infections. Hence, all have agreed to the need for more sensitization and health promotion on antibiotic resistance to the communities to increase knowledge.

\subsection{Health workers' behavior of using antibiotic}

The study found that only $26.01 \%$ of respondents gave the right answers on whether antibiotics could be used when having common cold and wherein auxilary nurses performing better than the other trained cadres $54.05 \%(\chi 2=23.6$, $\mathrm{p}=<0.0001$ ). This finding is the same as the one done in India where majority of health care worker were confused with the right treatment for cold especially among nurses $[18,19]$.Majority $(91.82 \%)$ of the respondents provided the correct answers to the questions on whether antibiotics could be used when having acute bronchitis, with doctors and public health officers performing significantly lower at $61.54 \%$ and $66.67 \%$ respectively. Most (83.11\%) of the respondents provided the correct answers to the questions on whether antibiotics could be used when coughing up yellow/green sputum, but there was no statistically significant difference in the performance of the different cadres $(\chi 2=2.92$, $\mathrm{p}=0.712$ ). $87 \%$ of respondents provided the correct answers to the questions on whether antibiotics could be used to 
treat sore throat, but there was no statistically significant difference in the performance of the different cadres $(\chi 2$ $=9.79, \mathrm{p}=0.081) .73 .09 \%$ of respondents provided the correct answer to the question on whether antibiotics could be used to treat cough with fever, however, the attitude of health care workers in addressing cold with fever was poor [19] but there was no statistically significant difference in the performance of the different cadres $(\chi 2=5.62$, $p=0.345)$.0n whether antibiotics could be used when having a congested nose with headache, only $30.88 \%$ of respondents gave the right answer, with public health officers performing significantly better than the other cadres at $66.67 \%(\chi 2=17.4$, $\mathrm{p}=0.004) .58 .53 \%$ of the respondents provided the correct answer to the question on whether antibiotics could be used when having acute bronchitis, with laboratory personnel and auxiliary nurses performing significantly better at $83.33 \%$ and $80 \%$ respectively $(\chi 2=13.8, p=0.017)$. the question on whether antibiotics could be used to treat cough lasting 2 weeks or more, $76.82 \%$ of respondents provided the correct answer but there was no statistically significant difference in the performance of the different cadres $(\chi 2=9.97, p=0.076)$. Therefore, the need for refresher training on prudent treatment of infectious diseases for the health care workers especially nurses and medical doctors' prescribing drug for patients in the country.

\subsection{Limitation}

Majority of the interviewed respondents were nurses and disproportionate distribution of other cadres which could bias the interpretation and comparison of variables by cadre

\section{Conclusion}

The study found that majority of the health care workers have knowledge about antibiotic resistance and are aware of antibiotic abuse which could contribute to the development of antibiotic resistance in the country. However, they were found to be less aware of the cost involved in the treatment of multidrug resistance patients using newer effective antibiotics. Moreover, some of the health care workers have a misconception on the treatment of viral infections such as common cold. The study found a disproportionate distribution of the trained health workers especially Doctors who are mainly found in the city exposing patients in rural communities more likely to poor patient care. A good percentage of the respondents were auxiliary nurses who were found to be less knowledgeable about antibiotic resistance though their attitude and practices were good. The respondents recommended awareness campaigns in both schools, hospitals and in communities to be conducted. Increase health promotion on the rational use of antibiotics for patients by the Health Promotion Directorate.

\section{Compliance with ethical standards}

\section{Acknowledgments}

We wish to thanks all the field workers and the health care workers for their participation in the study.

\section{Disclosure of conflict of interest}

All the authors have declared no conflict of interest.

\section{Funding Source}

This study was funded by World Health Organization, Country Office, and The Gambia with the funding number: P0 201612856

\section{Statement of informed consent}

Informed consent was obtained from all the participants included in the study.

\section{References}

[1] World Health Organization. Monitoring global progress on addressing antimicrobial resistance: analysis report of the second round of results of AMR country self-assessment survey. 2018.

[2] Bischoff S, Walter T, Gerigk M, Ebert M, Vogelmann R. Empiric antibiotic therapy in urinary tract infection in patients with risk factors for antibiotic resistance in a German emergency department. BMC infectious diseases. Dec. 2018; 18(1): 56. 
[3] Tenney J, Hudson N, Alnifaidy H, Li JT, Fung KH. Risk factors for aquiring multidrug-resistant organisms in urinary tract infections: A systematic literature review.

[4] Abera B, Kibret M, Mulu W. Knowledge and beliefs on antimicrobial resistance among physicians and nurses in hospitals in Amhara Region, Ethiopia. 2014; $1-7$.

[5] García C, Llamocca LP, García K, et al. Knowledge, attitudes and practice survey about antimicrobial resistance and prescribing among physicians in a hospital setting in Lima, Peru. BMC Clin Pharmacol. 2011; 11(1): 18.

[6] Chaw PS, Höpner J, Mikolajczyk R. The knowledge, attitude and practice of health practitioners towards antibiotic prescribing and resistance in developing countries-A systematic review. Journal of clinical pharmacy and therapeutics. 29 Jun 2018.

[7] Sanneh B, Kebbeh A, Jallow HS, Camara Y, Mwamakamba LW, Ceesay IF, Barrow E, Sowe FO, Sambou SM, Baldeh I, Jallow A. Prevalence and risk factors for faecal carriage of Extended Spectrum $\beta$-lactamase producing Enterobacteriaceae among food handlers in lower basic schools in West Coast Region of The Gambia. PLoS One. 2018 Aug 13; 13(8):e0200894.

[8] Bojang A, Camara B, Jagne Cox I, Oluwalana C, Lette K, Usuf E, Bottomley C, Howden BP, D’Alessandro U, Roca A. Long-term Impact of Oral Azithromycin Taken by Gambian Women During Labor on Prevalence and Antibiotic Susceptibility of Streptococcus pneumoniae and Staphylococcus aureus in Their Infants: Follow-up of a Randomized Clinical Trial. Clinical Infectious Diseases. 2018 Sep 28;67(8):1191-7.

[9] Adegbola RA, Hill P, Baldeh I, Otu J, Sarr R, Sillah J, Lienhardt C, Corrah T, Manneh K, Drobniewski F, McAdam KP. Surveillance of drug-resistant Mycobacterium tuberculosis in The Gambia. The International Journal of Tuberculosis and Lung Disease. 1 Apr 2003; 7(4): 390-3.

[10] Secka O, Berg DE, Antonio M, Corrah T, Tapgun M, Walton R,et al. Antimicrobial susceptibility and resistance patterns among Helicobacter pylori strains from The The Gambia, West Africa. Antimicrobial agents and chemotherapy. 1 Mar 2013; 57(3): 1231-7,

[11] Darboe S, Secka O. Prevalence of Panton-Valentine Leukocidin (PVL) and antimicrobial resistance in communityacquired clinical Staphylococcus aureus in an urban Gambian hospital: a 11-year period retrospective pilot study. Frontiers in Cellular and Infection Microbiology. 2019; 9: 170.

[12] Dione MM, Ikumapayi U, Saha D, Mohammed NI, Adegbola RA, Geerts S, Ieven M, Antonio M. Antimicrobial resistance and virulence genes of non-typhoidal** Salmonella** isolates in The Gambia and Senegal. Journal of infection in developing countries. 2011; 5(11): 765-75.

[13] Okomo UA. Neonatal Infections; a hospital-based study in The Gambia examining aetiology and associated maternal Colonisation (Doctoral dissertation, London School of Hygiene \& Tropical Medicine).

[14] Chaw PS, Schlinkmann KM, Raupach-Rosin H, Karch A, Pletz MW, Huebner J, Nyan O, Mikolajczyk R. Antibiotic use on paediatric inpatients in a teaching hospital in the Gambia, a retrospective study. Antimicrobial Resistance \& Infection Control. Dec 2018; 7(1): 82.

[15] Okomo UA, Garba D, Fombah AE, Secka O, Ikumapayi UN, Udo JJ, Ota MO. Bacterial isolates and antibiotic sensitivity among Gambian children with severe acute malnutrition. International journal of pediatrics. 14 Jul 2011.

[16] The Gambia Joint External Evaluation (JEE) report, 25-29 September 2017. https://www.afro.who.int/mediacentre/events/gambia-joint-external-evaluation-jee-25-29-september-2017

[17] Baadani AM, Baig K, Alfahad WA, Aldalbahi S, Omrani AS. Physicians' knowledge, perceptions, and attitudes toward antimicrobial prescribing in Riyadh, Saudi Arabia. 2015; 36(5): 613-619.

[18] Sampath S, Venoukichenane V. Knowledge. Attitude and Practice of antibiotics usage among Health care personnel in a Tertiary care hospital. 2016; 4: 3294-3298.

[19] Sadasivam K, Chinnasami B, Ramraj B, Karthick N, Saravanan A. Knowledge, attitude and practice of paramedical staff towards antibiotic usage and its resistance. Biomedical and Pharmacology Journal. 28 Apr 2016; 9(1): 33743. 